\title{
Agreement Between Experts Regarding Assessment of Postoperative Urinary Elimination Nursing Outcomes in Elderly Patients
}

Graziele Ribeiro Bitencourt, MS, RN, Luise de Almeida Ferreira Alves, MS, RN, Rosimere Ferreira Santana, PhD, RN, and Marcos Venicios de Oliveira Lopes, PhD, RN

Graziele Ribeiro Bitencourt, MS, RN, is a Medical-Surgical Nursing Specialist, Gerontological Clinical Nurse Specialist at School of Nursing, Universidade Federal Fluminense, Niterói, Rio de Janeiro, Brazil, Luise de Almeida Ferreira Alves, MS, $R N$, is an Oncological Nursing Specialist, Gerontological Clinical Nurse Specialist at School of Nursing, Universidade Federal Fluminense, Niterói, Rio de Janeiro, Brazil, Rosimere Ferreira Santana, PhD, RN, is an Associate Professor at School of Nursing, Universidade Federal Fluminense, Niterói, Rio de Janeiro, Brazil, and Marcos Venicios de Oliveira Lopes, PhD, RN, is an Associate Professor in the Department of Nursing, Universidade Federal do Ceará, Fortaleza, Brazil.

\section{Search terms:}

Elderly, nursing assessment, nursing diagnosis, nursing outcome, surgical nursing, urinary system

\section{Author contact:}

gra_uff@yahoo.com.br, with a copy to the Editor: journal@nanda.org
PURPOSE: This study aims to verify the interrater reliability for indicators of the Nursing Outcomes Classification of urinary elimination.

METHODS: A total of 103 elderly postoperative patients were followed by two nurses with specialized training in medical-surgical and gerontological nursing. FINDINGS: The agreement of evaluators was based on interpretation of the Krippendorff's alpha coefficient, for complete emptying of the bladder (.928) and presence of leukocytes (.885). The amount of urine (.262), density (.425), and urinary frequency (.307) had the lowest rates of agreement.

IMPLICATIONS FOR NURSING PRACTICE: Analysis of urinary elimination could help in clinical follow-up of elderly postoperative patients and selection of nursing interventions.

PROPÓSITO: Este estudo se propõe a verificar a confiabilidade inter-avaliador para indicadores do resultado NOC Eliminação urinária.

MÉTODOS: Um total de 103 pacientes idosos em pós-operatório foram seguidos por duas enfermeiras com treinamento específico em enfermagem medicocirúrgica e gerontológica.

ANÁLISE DOS DADOS: A concordância dos avaliadores foi baseada na interpretação do coeficiente Alpha do Krippendorff para o esvaziamento completo da bexiga (0.928) e presença de leucócitos (0.885). A quantidade de urina (0.262), densidade (0.425), e frequência urinária (0.307) apresentaram os menores índices na avaliação.

IMPLICAÇõES PARA A PRÁTICA DE ENFERMAGEM: Análise da eliminação urinária pode auxiliar no seguimento clínico de pacientes idosos em pósoperatório e selecionar intervenções de enfermagem.
Standardized procedures provide guidance regarding questions, and clarify institutional rules and guidelines that should be followed by healthcare professionals. These actions allow a care directed to the specific needs of the patient, increasing the efficiency of nursing and reducing health costs. However, standardized languages should be clinically tested for their consistency and reliability for nurses to feel confident to use them.
In this context, the Nursing Outcomes Classification (NOC) can be used to evaluate the condition of the patient using a five-point, Likert-type scale to analyze various indicators, which allows the current status of the patient to be measured and facilitates the identification of changes based on differences in scores over time (Moorhead, Johnson, Mass, \& Swanson, 2013). This classification includes the outcome urinary elimination (0503), which is 
defined as "disposal and storage of urine" and its indicators are odor, quantity, color, transparency, fluid intake, complete emptying of the bladder, particulates in urine, blood in urine, painful urination, burning on urination, urinary hesitancy, nocturia, and urinary continence. Moreover, it facilitates the evaluation of the patient who does not always meet the scoring criteria as identified in levels 1 through 5 of the classification scale.

Several studies were developed to establish criteria for scoring clinical indicators in elderly postoperative patients. Xavier et al. (2011) used subjective scales for evaluation of pain and health status; Fogazzi, Verdesca, and Garigali (2008) used quantitative instruments for urologic analysis; and Caldas, Conceição, Jose, and Correa (2010) used behavioral therapy for urinary incontinence in elderly women. In addition, Jamieson (2005) assessed urinary dysfunction among stroke patients based on residual volume measurement and a "dipstick" test.

Thus, the NOC outcome urinary elimination can assist nurses to obtain a more adequate assessment of the impairment level; checking the reliability of its indicators is an important step for clinical validation. Reliability is based on repeated or paired measures that reproduce similar results (Oliveira, Oliveira, \& Bergamaschi, 2006). Therefore, studies using the analysis of agreement among experts can help to determine the applicability of criteria for indicators of nursing outcomes, such as urinary elimination. The objective of this study, therefore, was to verify the interrater reliability for indicators of the NOC outcome of urinary elimination.

\section{Methods}

A longitudinal quantitative approach was used to compare the assessment results from two expert nurse reviewers who monitored clinical changes in urinary elimination based on the 1 to 5 NOC scale in elderly postoperative patients.

For the specificity of analysis in evaluating urinary elimination in the elderly, the selection criteria established for the choice of experts were having a graduate degree in gerontological nursing, and having completed more than 5 years in clinical surgical nursing.

Those expert nurse reviewers compared the findings, concordance, and feasibility of using the criteria for analysis of the nursing outcome indicators, based on a previous study with operational definitions, as reported by Bitencourt and Santana (2012). These operational definitions can be found in supplemental information provided with this article. To this end, the expert nurse reviewers were trained in standardized collection procedures and analysis for evaluating the criteria of the study subjects over a period of 3 months. This training consisted of the following steps:

1. Lectures on urinary system function in elderly patients and urinary assessment tests.
2. Analysis of the integrative review of indicators for urinary elimination suggested by Bitencourt and Santana (2012): urine odor, amount of urine, urine color, transparency of urine, fluid intake, complete emptying of the bladder, leukocytes, nitrate, urobilinogen, protein, density, ketone bodies, bilirubin, glucogen, visible blood in urine, painful urination, burning on urination, hesitation to urinate, urinary frequency, nocturia, and urinary continence.

3. Discussion on standard operating procedures developed for this study, including criteria and evaluation scores, urinary elimination NOC outcome with operational definitions (see Table 1), along with the scores as suggested by Bitencourt and Santana (2012).

4. Next, the trainer accompanied the nurses to the study site for 3 days and compared 10 patients to discuss their analysis. The patients assessed in the pilot study were not included as study subjects.

Following training, the expert nurses reviewers simultaneously tracked 103 male and female individuals, $\geq 65$ years of age, who were hospitalized postoperatively. There were a total of 206 observations because two experts in medicalsurgical and gerontological nursing assessed each subject to increase the reliability of data. As a longitudinal study,

Table 1. Characteristics of Elderly Patients With Postoperative Impaired Urinary Elimination $(n=103)$

\begin{tabular}{|c|c|c|c|c|}
\hline & Male & Female & Total & \\
\hline Features & n (\%) & $n(\%)$ & n (\%) & $p$ value \\
\hline \multicolumn{5}{|l|}{ Age (years) } \\
\hline $65-74$ & $27(35.5)$ & $49(64.5)$ & 77 (73.8) & \multirow[t]{2}{*}{$.980^{a}$} \\
\hline $74-85$ & $7(26.0)$ & $20(74.0)$ & $26(27.2)$ & \\
\hline \multicolumn{5}{|l|}{ Marital status } \\
\hline Single & $6(24)$ & $19(76)$ & $25(24.3)$ & \multirow[t]{4}{*}{$.556^{b}$} \\
\hline Married & $16(32.6)$ & $33(67.4)$ & $49(47.6)$ & \\
\hline Widower & $6(46.1)$ & $7(53.9)$ & $13(12.6)$ & \\
\hline Divorced & $6(37.5)$ & $10(62.5)$ & $16(15.5)$ & \\
\hline \multicolumn{5}{|l|}{ Surgery ${ }^{d}$} \\
\hline General & $3(14.3)$ & $18(85.7)$ & $21(20.4)$ & \multirow[t]{8}{*}{$.001^{c}$} \\
\hline Gynecology & - & $12(11.7)$ & $12(11.7)$ & \\
\hline Mastology & - & $12(100)$ & $12(11.7)$ & \\
\hline Neurosurgery & - & $6(100)$ & $6(5.8)$ & \\
\hline Orthopedics & $9(50)$ & $9(50)$ & $12(11.7)$ & \\
\hline Thoracic & $1(14.3)$ & $6(85.7)$ & $7(6.7)$ & \\
\hline Urology & 19 (79.2) & $5(20.8)$ & $24(23.3)$ & \\
\hline Vascular & $2(22.2)$ & $7(77.8)$ & $9(8.7)$ & \\
\hline \multicolumn{5}{|c|}{ Postoperative days } \\
\hline $1-3$ & $15(35.7)$ & $27(64.3)$ & $42(40.8)$ & \multirow[t]{3}{*}{$.829^{a}$} \\
\hline $3-5$ & $16(28.6)$ & $40(71.4)$ & $56(54.4)$ & \\
\hline$>5$ & $3(60)$ & $2(40)$ & $5(4.8)$ & \\
\hline \multicolumn{5}{|c|}{ Preoperative impaired urinary elimination } \\
\hline Yes & $21(52.5)$ & $19(47.5)$ & $40(38.8)$ & \multirow[t]{2}{*}{$.001^{\mathrm{b}}$} \\
\hline No & $13(20.6)$ & $50(79.4)$ & $63(61.2)$ & \\
\hline
\end{tabular}




\section{G. R. Bitencourt et al. Assessment of Postoperative Urinary Elimination Nursing Outcomes}

Table 2. Diagnosis of Postoperative Impaired Urinary Elimination in Elderly Patients $(n=103)$

\begin{tabular}{|c|c|c|c|c|c|}
\hline & \multicolumn{2}{|l|}{ Sex } & \multicolumn{3}{|c|}{ Age (years) } \\
\hline Variables & $n(\%)$ & $n(\%)$ & $n(\%)$ & $n(\%)$ & $\begin{array}{l}\text { Total } \\
\text { n (\%) }\end{array}$ \\
\hline \multicolumn{6}{|l|}{ Defining characteristics } \\
\hline Dysuria & $33(35.9)$ & $58(64.1)$ & $71(76.3)$ & $22(23.7)$ & $93(90.3)$ \\
\hline Frequency (polyuria) & $2(20.0)$ & $8(80.0)$ & $6(75.0)$ & $4(25.0)$ & $8(7.8)$ \\
\hline Urinary retention & $1(33.3)$ & $2(66.7)$ & $2(100)$ & - & $2(1.9)$ \\
\hline \multicolumn{6}{|l|}{ Related factors } \\
\hline Urinary tract infection & $7(50.0)$ & $7(50.0)$ & $8(47.3)$ & $5(35.7)$ & $14(13.6)$ \\
\hline Multiple causes & $22(28.2)$ & $56(71.8)$ & $60(76.9)$ & $18(23.0)$ & $78(75.7)$ \\
\hline Anatomic obstruction & $2(66.7)$ & $1(33.3)$ & $3(100)$ & - & $3(2.9)$ \\
\hline Total & - & - & - & - & $103(100)$ \\
\hline
\end{tabular}

there were a total of 782.8 observations based on an average of 3.8 days of assessment for each subject.

All of the subjects were diagnosed with the NANDAInternational, Inc. nursing diagnosis, impaired urinary elimination (00016) (Herdman, 2012). All study subjects underwent the following three observations: preoperative to detect preexisting impaired urinary elimination, 1 day after surgery, and once throughout the hospitalization. Patients were assessed when they were admitted to one of the following surgical clinics at a teaching hospital in Brazil: general, mastology, vascular, urology, orthopedic, thoracic, gynecology, and neurosurgery.

The data are presented as descriptive and inferential statistics. A statistician compared the frequency, reliability, and validity of the measurement instruments. Frequency distribution, and statistical tests to compare these frequencies, included the Mann-Whitney, chi-square, and FisherFreeman-Halton. To determine the degree of agreement between nurse reviewers, we applied the index of Krippendorff's alpha coefficient. We use a cutoff of 0.7 to consider a satisfactory reliability level of the NOC scale indicators (Krippendorff, 2013).

This study is approved by the Institutional Review Board in accordance with the Declaration of Helsinki (approval number 0320.0.258.258-11). All subjects signed the terms of informed consent.

\section{Results}

The variables used to characterize the subjects investigated in this study, including age, gender (male and female), surgical specialty, and diagnosis of impaired preoperative urinary elimination, are shown in Table 1.

Of the 103 patients, the majority $(69,67 \%)$ were females, $77(73.8 \%)$ were between 65 and 74 years of age, $49(47.6 \%)$ were married, and $24(23.3 \%)$ underwent urologic surgery. A total of $56(54.4 \%)$ of the subjects were evaluated between 3 and 5 days postoperatively. Preoperative impaired urinary elimination was noted in 40 (38.8\%) patients, consisting of $21(52.5 \%)$ males and $19(47.5 \%)$ females. Male gender was associated with urologic surgery $(p=.001)$ and with the presence of preoperative impaired urinary elimination ( $p=.0012$ ) (Table 1).

As shown in Table 2, dysuria was a defining characteristic in $93(90.3 \%)$ of the elderly patients in the study for both sexes and age categories identified. Most of the cases presented with multiple causes that were associated with the use of anesthetics and postoperative conditions, such as immobility and fluid restriction.

The consistency of evaluators was based on interpretation of the Krippendorff's alpha coefficient, and was determined based on the values obtained at 1.0 (Table 3 ). Complete emptying of the bladder (.928), presence of leukocytes (.885), and pain during urination (.87) showed greater agreement between raters. The amount of urine (.262), density (.425), urinary frequency (.307), and nocturia (.404) had the lowest rates of agreement.

\section{Discussion}

The majority of females can be inferred based on elderly profiles indicating $55 \%$ of the elderly population as reported by Lisboa and Chianca (2012). The largest proportion of elderly individuals reside in Southeastern Brazil $(57.2 \%)$, which is where the present study was conducted. The ages of the subjects in this study align with that of Closs and Schwanke (2012). Regarding marital status, the elderly patients in this study may not reflect the demographics in Brazil and the Americas, where more elderly individuals are widowed.

The study showed that most of the elderly patients underwent a urological surgical procedure. No recent surveys have been conducted to profile the elderly surgical specialty, but we can infer that, because this study analyzes 
Table 3. Indices of Agreement (Krippendorff's Alpha Coefficient) Between the Nurses' Assessment and Evaluation of Clinical Indicators

\begin{tabular}{|c|c|c|c|c|c|c|c|c|}
\hline \multirow[b]{2}{*}{ Indicators } & \multicolumn{8}{|c|}{ Assessment concordance } \\
\hline & 1st & 2nd & 3 th & 4 th & 5 th & 6 th & 7 th & General \\
\hline Urine odor & 0.796 & 0.938 & 0.952 & 0.700 & 0.848 & 0.904 & 0.833 & 0.785 \\
\hline Amount of urine & $0.588^{b}$ & $-0.122^{b}$ & 1.000 & 0.833 & $0.465^{\mathrm{b}}$ & 0.986 & 1.000 & $0.262^{b}$ \\
\hline Urine color & 0.830 & $-0.061^{\mathrm{b}}$ & 1.000 & 0.833 & 0.702 & 0.750 & 1.000 & $0.427^{b}$ \\
\hline Transparency of urine & 0.725 & $0.579^{b}$ & 0.976 & 0.700 & $0.472^{b}$ & 0.987 & 1.000 & $0.518^{b}$ \\
\hline Fluid intake & $0.410^{b}$ & 0.760 & 0.910 & 0.700 & $0.583^{b}$ & 0.810 & 0.833 & $0.441^{b}$ \\
\hline Complete emptying of the bladder & 0.752 & 1.000 & 1.000 & 1.000 & 1.000 & 1.000 & 1.000 & 0.928 \\
\hline Leukocytes & 0.996 & 0.937 & 1.000 & 0.833 & 0.823 & 0.997 & 0.833 & 0.885 \\
\hline Nitrate & 0.967 & 0.853 & 1.000 & 0.833 & 0.847 & 1.000 & 0.833 & 0.863 \\
\hline Urobilinogen & 1.000 & $0.663^{b}$ & 1.000 & 0.833 & 0.876 & 0.701 & 1.000 & 0.780 \\
\hline Protein & 0.842 & 0.920 & 1.000 & 0.833 & $0.148^{b}$ & 0.827 & 1.000 & $0.443^{b}$ \\
\hline Density & 0.715 & 0.966 & 0.750 & 0.700 & $0.416^{b}$ & $0.503^{b}$ & 1.000 & $0.425^{b}$ \\
\hline Ketone bodies & 0.983 & $0.353^{b}$ & 1.000 & 1.000 & 0.723 & 1.000 & 1.000 & 0.736 \\
\hline Bilirubin & 1.000 & $0.667^{b}$ & 1.000 & 0.833 & 0.800 & 1.000 & 1.000 & 0.782 \\
\hline Glucogen & 0.956 & $0.578^{b}$ & 1.000 & 0.833 & 0.878 & 1.000 & 1.000 & 0.806 \\
\hline Visible blood in urine & 0.787 & 0.768 & 1.000 & 1.000 & 0.762 & 0.703 & 1.000 & 0.743 \\
\hline Painful urination & 0.930 & 0.829 & 1.000 & a & 0.917 & 0.703 & 1.000 & 0.870 \\
\hline Burning on urination & 0.945 & $0.579^{b}$ & 1.000 & a & 0.860 & 1.000 & 1.000 & 0.869 \\
\hline Hesitation to urinate & 1.000 & $0.280^{b}$ & 1.000 & $0.000^{b}$ & 0.920 & $0.603^{b}$ & 1.000 & $0.692^{b}$ \\
\hline Urinary frequency & 0.710 & $-0.225^{b}$ & 1.000 & 0.700 & $0.325^{b}$ & 0.774 & 0.833 & $0.307^{b}$ \\
\hline Nocturia & $0.564^{b}$ & $0.354^{b}$ & 1.000 & $0.000^{b}$ & $0.315^{b}$ & 0.764 & 0.833 & $0.404^{b}$ \\
\hline Urinary continence & 0.806 & 0.807 & 1.000 & a & 0.805 & 1.000 & 1.000 & 0.865 \\
\hline
\end{tabular}

${ }^{a}$ Calculations were not possible due to insufficient sample.

${ }^{b}$ Low agreement.

urinary elimination after surgery, nurses specializing in urology may benefit from these results. The presence of visible blood and particulates in the urine following this type of surgery deserves attention and indicates a diagnosis of impaired urinary elimination, which may require nursing intervention and outcome assessment.

Mevcha and Drake (2010) suggested that intra-and postoperative factors may interfere with the elucidation of these factors. The use of anticholinergic drugs or analgesics, type of surgery, intravenous therapy, position during urination, and loss of patient privacy can impair urinary elimination in the postoperative period, and are reflective of the multiple causes identified as related factors.

The primary complaint was that dysuria might represent complications, such as incomplete emptying of the bladder, urinary tract infection, urinary incontinence, and urinary retention. Matthews and Lancaster (2011) in their study confirmed the association between the presence of dysuria and urinary tract infection.

Standardization can be inferred by analyzing the agreement between evaluators regarding indicators. According to Barrat (2007), the operational definitions for most of these indicators (e.g., leukocytes, painful urination, odor, nitrates, urobilinogen, and bilirubin) can be determined using reagent strips, where a change in color represents an increase or decrease in these parameters. This monitoring reduces subjective interpretations by the various professionals involved in patient care.

Accuracy can be improved by eliminating the subjective element of identifying these changes in color by the human eye. Reactive urine strips are a quick, simple way of performing 10 or more clinically important biochemical analyses, including those for kidney disease and urinary tract infections. Furthermore, it allows a procedure step to assess renal function and provides clues about the etiology of the disorder. As suggested by Sundvall and Gunnarsson (2009), simplicity, low cost, and ease of obtaining samples for analysis make it appealing in routine examination. Measurement of residual urine volume contributed to the standardization of observations through catheterization or ultrasound.

In some countries, nurses are not allowed to use reactive urine strips, and any sample must be sent to the lab because the interpretation of the colored strips may vary. However, training of nurses could provide an answer for better clinical settings and accurate reading.

As described in Du Moulin, Hamers, Ambergen, and Halfens (2009), ultrasound represents a noninvasive measurement tool. Catheterization after voiding to remove residual urinary volume is another method. This parameter, however, cannot be measured more than 20 min after an increase in urinary elimination, due to the risk of false positive urinary retention.

The survey also indicated that the raters were in agreement regarding painful urination. For analysis of this indicator, the Subjective Pain Scale measurement may be used. According to Haddad, Saldanha, and Driusso (2008), scores in elderly patients can range from 0 in less severe cases to 10 points in severe pain cases.

Because pain is a subjective indicator, it was expected to present greater disagreement than was observed. However, 


\section{G. R. Bitencourt et al. Assessment of Postoperative Urinary Elimination Nursing Outcomes}

patient training and measurement using a subjective scale contributed to the results. The perception of pain and selfobservation is acquired through learning processes, and oral or written reports are ways to describe and communicate this perception. Words (oral or written) represent the instruments used to assist in evaluation because they allow access to the psychological aspects associated with pain, intensity, and triggers.

The amount of urine, fluid intake, urinary frequency, and nocturia showed less agreement between the raters. When the patient has fluid balance and intermittent catheterization, standardization of these indicators is favored due to precise measurements of the input and output of liquids.

Oliveira, Guedes, and Lima (2010) suggested methods that can accurately assess the fluid and electrolyte balance and facilitate anticipation of required nursing care. According to Gaspar (2011), intake and elimination of fluid and regulation of renal and pulmonary functions inherent to the daily identification of postoperative complications can be investigated.

So it confirms the importance of fluid balance as part of daily nursing care. It becomes possible to identify clinical complications in the postoperative for monitoring indicators of the amount of urine, fluid intake, and urinary frequency.

Potter and Perry (2012) considered $1.5 \mathrm{~L}$ to $2.0 \mathrm{~L}$ of output per day to be normal, while less than $1.5 \mathrm{~L}$ could indicate a risk of complications. Patients are expected to excrete $1 \mathrm{ml} / \mathrm{kg} / \mathrm{hr}$. However, absence of this balance requires the patient to report these measurements, which can increase the risk of inaccuracy. The nursing staff can assess the urinary elimination of patients. Oliveira et al. (2010) reported that the information, knowledge, and skills to facilitate accurate assessment of fluid balance could be used to determine possible changes, which facilitates anticipation of nursing care. Therefore, it is necessary to use clinical reasoning and research to validate the accuracy of the data and the reliability of sources, including monitoring, identification, and interviewing of the patient.

Quantitative indicators of urinary elimination, such as the amount of urine, fluid intake, urinary frequency, and nocturia, through catheterization and fluid balance, can increase the accuracy of urine assessments. If these indicators are not available, information obtained from the patient can be useful, although uncertain. Nursing records and continuous observation can promote and improve accuracy when assessing these indicators.

The operational definition indicated the use of reagent strips for evaluation. However, the urinary density results showed disagreement between evaluators. This finding was unexpected. In Brazil, there is no required certification or competency established for individuals to read the reactive strips. To reduce the chance of errors, we used the same brand strip in all subjects and the expert nurse reviewers faithfully followed the protocol for use.

Regarding standardization of the research data, Silva, Saboia, and Teixeira (2009) suggest that observations may vary according to professional opinions, which can influence assessments. To reduce this variability, consistency in nursing staff and standard methods of determining urinary elimination should be used to analyze indicators of urinary impairment.

\section{Conclusion}

This study describes the validation of NOC indicators based on agreement of evaluators, with the objective to make clear how nurses evaluate each indicator and can use this classification in clinical practice. The study identified the need to validate the NOC indicators between expert nurse reviewers, especially as the NOC scale measures, determines, and objectively evaluates the NOC variation 1-5. Thus, our findings showed that NOC classification can be useful for monitoring the clinical changes related to urinary elimination.

The high agreement for the indicators urine odor, leukocytes, nitrate, and visible blood in urine can be related to the use of operational definitions based on the values of the reagent strip. The high agreement in painful urination and urinary continence, despite subjective indicators, can be associated with the clarity of operational definitions of these indicators used to determine each level on the NOC scale. The majority of observed disagreements were associated with the data related to systematic records of the nursing staff, such as the amount of urine and urinary frequency.

Recommendations of the NOC stipulate the measure levels of each proposed criterion based on previous studies. This would facilitate its use in clinical practice by different nurses. Besides, the evaluation score levels are not strictly 1-5, which can vary according to the parameters of certain evaluations. As an example, urinary density was adjusted to five items, but originally the reagent strips displayed four classification levels. Furthermore, future studies applying these criteria in patients in other settings, such as intensive care units, as well as in other age groups, should be performed.

\section{References}

Barrat, J. (2007). What to do with patients with abnormal dipstick urinalysis. Medicine Journal, 35, 365-367.

Bitencourt, G. R., \& Santana, R. F. (2012). Conceptual validation of the nursing outcome urinary elimination in elderly surgical. [Validação conceitual do resultado de enfermagem de eliminação urinária em idosos cirúrgicos]. In T. H. Herdman (Ed.), NANDA International 2012 Conference Abstract ( $\mathrm{p}$. 40). TX: NANDA-I.

Caldas, C. P., Conceição, I. R. S., Jose, R. M. C., \& Correa, B. M. (2010). Behavioral therapy for urinary incontinence of elderly woman: A nursing action [Terapia comportamental para mulher idosa: uma ação do enfermeiro]. Texto \& Contexto Enfermagem, 19, 783-788.

Closs, V. E., \& Schwanke, C. H. A. (2012). Aging index development in Brazil, regions, and federative units from 1970 to 2010 [A evolução do índice de envelhecimento no Brasil, nas suas regiões e unidades federativas no período de 1970 a 2010]. Revista Brasileira de Geriatria e Gerontologia, 15(3), 443-458.

Du Moulin, M. F., Hamers, J. P., Ambergen, A. W., \& Halfens, R. J. (2009). Urinary incontinence in older adults receiving home care diagnosis and strategies. Scandinavian Journal of Caring Science, 23(2), 222-230. 
Fogazzi, G. B., Verdesca, S., \& Garigali, G. (2008). Urinalysis: Core curriculum. American Journal of Kidney Diseases, 51, 1052-1067.

Gaspar, P. M. (2011). Comparison of four standards for determining adequate water intake of nursing home residents. Research and Theory for Nursing Practice, 25, 11-22.

Haddad, M., Saldanha, M. E. S., \& Driusso, P. (2008). Comparison of quality of life for different types of female urinary incontinence [Comparação da qualidade de vida nos diferentes tipos de incontinência urinária feminina]. Revista Brasileira de Fisioterapia, 3, 116-122.

Herdman, T. H. (Ed.). (2012). NANDA international nursing diagnoses: Definitions and classification, 2012-2014. Oxford: Wiley-Blackwell.

Jamieson, K. (2005). Urinary dysfunction: Assessment and management in stroke patients. Nursing Standard, 25, 49-55.

Krippendorff, K. (2013). Content analysis: An introduction to its methodology. Thousand Oaks, CA: Sage.

Lisboa, C. R., \& Chianca, T. C. M. (2012). Epidemiological, clinical and of functional independence profile of an institutionalized elderly population [Perfil epidemiológico, clínico e de independência funcional de uma população idosa institucionalizada]. Revista Brasileira de Enfermagem, 65(3), 482-488.

Matthews, S. J., \& Lancaster, J. W. (2011). Urinary tract infections in the elderly population. American Journal of Geriatric Pharmacotherapy, 9(5), 286-309.

Mevcha, A., \& Drake, M. J. (2010). Etiology and management of urinary retention in women. Indian Journal of Urology, 26, 230-235.
Moorhead, S., Johnson, M., Mass, M., \& Swanson, E. (Eds.). (2013). Nursing Outcomes Classification (NOC): Measurement of health outcomes (5th ed.). St. Louis, MO: Mosby Elsevier.

Oliveira, N. S., Oliveira, J. M., \& Bergamaschi, D. P. (2006). Agreement among evaluators in the selection of articles in a systematic review [Concordância entre avaliadores na seleção de artigos em revisões sistemáticas]. Revista Brasileira de Epidemiologia, 9, 309-315.

Oliveira, S. K. P., Guedes, M. C., \& Lima, F. (2010). Hydric balance in nursing clinical practice in a coronary unit [Balanço hídrico na prática clínica de enfermagem em unidade coronariana]. Revista Rene, 11, 201-212.

Potter, P. A., \& Perry, A. G. (2012). Fundamentals of nursing. St. Louis, MO: Mosby Elsevier.

Silva, C. M. C., Saboia, V. M., \& Teixeira, E. R. (2009). Teaching the physical examination in its technical and subjective dimensions [O ensino do exame físico em suas dimensões técnicas e subjetivas]. Texto \& Contexto Enfermagem, 18, 458-465.

Sundvall, P. D., \& Gunnarsson, R. K. (2009). Evaluation of dipstick analysis among elderly residents to detect bacteriuria: A cross-sectional study in 32 nursing homes. BMC Geriatrics, 27, 9-32.

Xavier, T. T., Torres, G. V., Reis, L. A., Silva, R. A. R., Costa, I. K., \& Fernandes, M. F. R. P. (2011). Post-surgical health and pain assessment for elderly submitted to cardiac surgery [Avaliação de saúde e da dor no pósoperatório de idosos submetidos à cirurgia cardíaca]. Texto \& Contexto Enfermagem, 20, 232-237. (spe). 